\title{
CATACANDINS, NOVEL ANTICANDIDAL ANTIBIOTICS OF BACTERIAL ORIGIN
}

\author{
Edward Meyers*, Raymond Cooper ${ }^{\dagger}$, Loretta Dean, Janice H. Johnson, \\ Dorothy S. Slusarchyk, William H. Trejo and Pushpa D. Singh \\ The Squibb Institute for Medical Research, \\ Princeton, New Jersey 08540, U.S.A. \\ (Received for publication August 5, 1985)
}

\begin{abstract}
Two novel antibiotics, catacandin A and catacandin B, were isolated from the fermentation broth of the bacterium, Lysobacter gummosus, by extraction and adsorption, reverse-phase and gel filtration chromatography. On the basis of their physico-chemical properties, they are acyltetramic acids that are easily distinguishable from others in this class. Catacandin A and catacandin B possess good anticandidal activity.
\end{abstract}

It is becoming increasingly evident that bacteria can produce a wide variety of antibiotic types, a biosynthetic ability once thought to be the domain of the Actinomycetales. In recent years, bacteria have been shown to produce $\beta$-lactam antibiotics ${ }^{1)}$, a nucleoside antibiotic ${ }^{2)}$, aminoglycosides ${ }^{3)}$, amino acid analogs ${ }^{4}$, etc. In addition to structural diversity, bacterially-produced antibiotics encompass a wide variety of antibiotic activities, from narrow to broad spectrum, to those with antifungal properties.

These considerations have led us to examine bacteria for the production of novel compounds with anticandidal activity. In the course of this screening effort, we found two novel antifungal agents. One, catacandin, is the subject of this report; the other, xylocandin, will be reported elsewhere ${ }^{5}$.

\section{Taxonomy}

The strain producing catacandin was originally isolated from a soil sample taken on the slopes of Mt. Etna, Sicily. The taxonomic characteristics of this strain are as follows:

\section{Morphology}

The organism is a long, slender Gram-negative rod with rounded rather than tapered ends. Some chain formation is evident. It is motile by means of gliding, leaving slime trails on the agar surface. No fruiting bodies are formed.

\section{Culture Characteristics}

Liquid cultures are viscous and agar cultures are mucilaginous. Colonies on sucrose $0.25 \%$, yeast extract $0.5 \%$ agar are yellow and transparent with scalloped, colorless edges that spread in an irregular manner.

\section{Biochemical Reactions}

The organism is capable of lysing eukaryotic cells (e.g., Saccharomyces cerevisiae) and is proteolytic, as evidenced by clearing of the opaqueness of a skim-milk acetate agar medium. It produces catalase, oxidase and phosphatase and is able to utilize citrate as the sole source of carbon for growth.

\footnotetext{
$\dagger$ Present address: Schering Corporation, 60 Orange Street, Bloomfield, New Jersey 07003, USA.
} 
It does not hydrolyze starch; it does produce acid from glucose, cellobiose, sucrose (delayed) and lactose, but not from glycerol or mannitol. The organism is lipolytic on Tween 20 and Tween 80 . It does not produce water-soluble pigments and it grows well on eosin-methylene blue agar. The $\mathrm{G}+\mathrm{C}$ content of the DNA is $66.9 \mathrm{~mol} \%$, as determined by the thermal denaturation method.

Based upon morphological, cultural and biochemical properties, the organism was identified as Lysobacter gummosus, in accordance with the description by CHRISTENSEN and Cook ${ }^{8)}$. The culture has been deposited in the American Type Culture Collection, Rockeville, Maryland and has the accession number, ATCC 39472.

\section{Production}

L. gummosus ATCC 39472 was maintained by storage in a mechanical freezer at $-90^{\circ} \mathrm{C}$. When needed, working stock cultures were prepared on agar slants composed of yeast extract $1 \%$, peptone $2 \%$, glucose $2 \%$ and agar $1.5 \%$. The slants were incubated at $25^{\circ} \mathrm{C}$ for 16 to 18 hours and used to inoculate germinator flasks containing $100 \mathrm{ml}$ of medium in 500-ml Erlenmeyer flasks. This medium consisted of yeast extract $0.4 \%$, malt extract $1 \%$ and dextrose $0.4 \%$. The germinators were incubated overnight ( 18 hours) at $25^{\circ} \mathrm{C}$ on a rotary shaker operating at $300 \mathrm{rpm}$ with a $5-\mathrm{cm}$ stroke, and then used to inoculate $(1 \%)$ the same medium (50 liters) in a 75 -liter Fermatron fermentor (New Brunswick Scientific, Edison, New Jersey, U.S.A.). The fermentation was run for 30 hours at $25^{\circ} \mathrm{C}$, with an air flow of 50 liters/minute and an agitation rate of $200 \mathrm{rpm}$. The fermentation and the subsequent isolation steps were monitored by paper-disc, agar-diffusion assay with Candida albicans SC5314 as the assay organism.

\section{Isolation Procedure}

The isolation and purification procedures for catacandins A and B are outlined in Fig. 1. The

Fig. 1. Isolation of catacandins A and B.

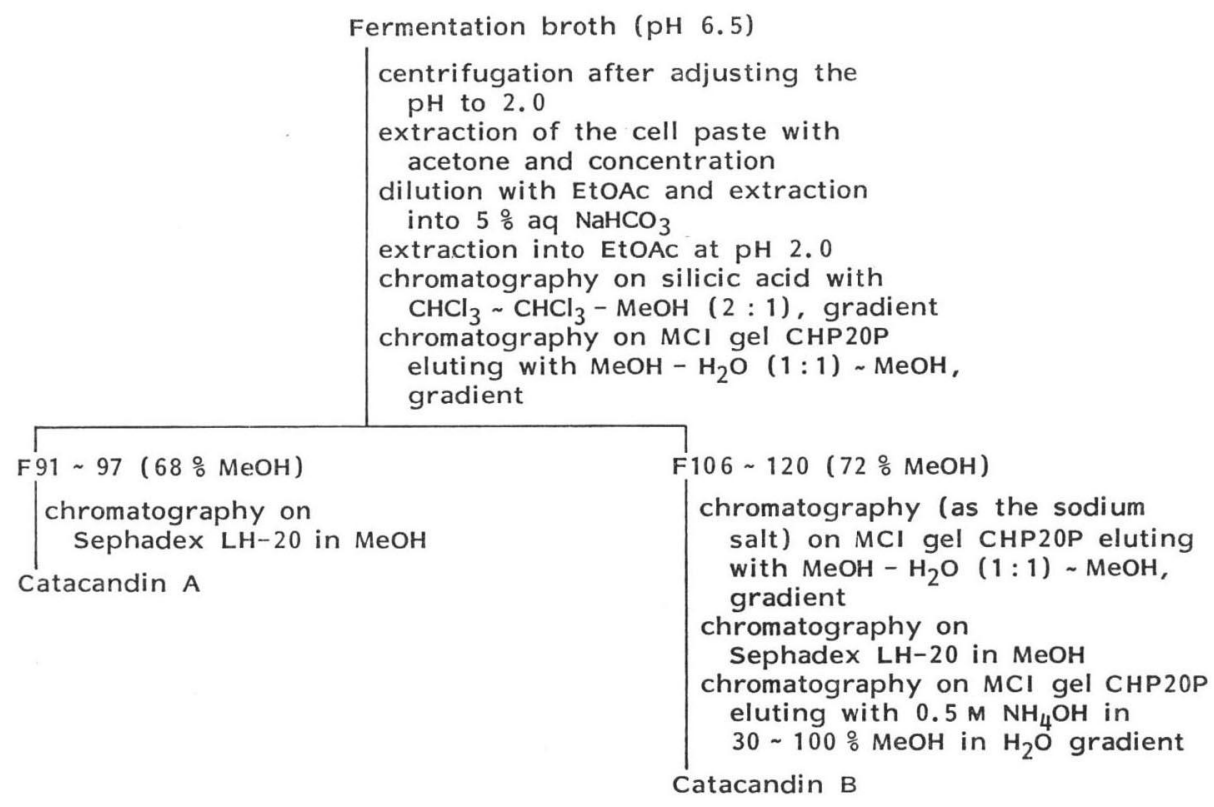


Table 1. Physico-chemical properties of catacandins A and B.

\begin{tabular}{|c|c|c|c|}
\hline & & Catacandin A & Catacandin B \\
\hline \multicolumn{2}{|l|}{$\mathrm{TLC}^{\mathrm{a}}$} & Rf 0.31 & Rf 0.42 \\
\hline \multicolumn{2}{|l|}{$\operatorname{IR}(\mathrm{KBr})^{\mathrm{b}} \mathrm{cm}^{-1}$} & $\begin{array}{l}3360,2940,2870,2375,1720 \\
1705,1655,1610,1460\end{array}$ & $\begin{array}{l}3320,2955,2860,2375,1720 \\
1705,1655,1600,1460\end{array}$ \\
\hline \multirow[t]{3}{*}{$\mathrm{UV} \mathrm{nm}\left(\mathrm{E}_{1 \mathrm{~m}}^{1 \%}\right)$} & $\mathrm{MeOH}$ & $\begin{array}{l}204(17,500), 258(30,500), \\
343(8,500)\end{array}$ & $\begin{array}{l}205(16,100), 236(15,600) \\
320(7,800)\end{array}$ \\
\hline & $0.01 \mathrm{M} \mathrm{HCl}$ in $\mathrm{MeOH}$ & $\begin{array}{l}205(14,000), 268(25,500), \\
358(13,500), 375(11,500)\end{array}$ & $215(17,500), 324(10,500)$ \\
\hline & $0.01 \mathrm{M} \mathrm{NaOH}$ in $\mathrm{MeOH}$ & $257(33,000), 340(8,500)$ & $236(15,800), 317(7,800)$ \\
\hline \multicolumn{2}{|c|}{ FAB-MS $\left((\mathrm{M}-\mathrm{H})^{-}, m / z\right)$} & 509.267 & 509.261 \\
\hline \multicolumn{2}{|c|}{ Molecular formula ${ }^{c}$} & $\mathrm{C}_{28} \mathrm{H}_{38} \mathrm{~N}_{2} \mathrm{O}_{6}$ & $\mathrm{C}_{28} \mathrm{H}_{38} \mathrm{~N}_{2} \mathrm{O}_{8}$ \\
\hline
\end{tabular}

a Silica gel, $\mathrm{CHCl}_{3}-\mathrm{MeOH}-\mathrm{NH}_{4} \mathrm{OH}, 6: 4: 1$.

b The IR spectral data for catacandins A and B were obtained on their sodium and ammonium salts, respectively.

c Molecular formulae were determined by FAB mass spectrometry.

fermentation broth, acidified to $\mathrm{pH} 2$ with hydrochloric acid, was centrifuged to separate solids from the supernate. Since most of the activity was associated with the solids, they were extracted with acetone and the resulting acetone extract concentrated in vacuo. The concentrate, diluted with ethyl acetate, was then extracted with $5 \%$ sodium bicarbonate. The bicarbonate solution was acidified to $\mathrm{pH} 2$ and the activity extracted into fresh ethyl acetate. The active components were further purified by a combination of normal-phase, reversed-phase and size-exclusion chromatography.

\section{Physico-chemical Properties}

The major component of the fermentation, catacandin A, is a methanol soluble, acidic antibiotic. Physico-chemical data are given in Table 1. The IR spectrum indicates the presence of ester (1720 $\left.\mathrm{cm}^{-1}\right)$ and amide $\left(1655 \mathrm{~cm}^{-1}\right)$ functions. The hypsochromic shift of the UV maximum at $375 \mathrm{~nm}$ to $340 \mathrm{~nm}$ in going from acidic to alkaline $\mathrm{pH}$ is characteristic of dienoyltetramic acid antibiotics, e.g., tirandamycin ${ }^{7)}$. The molecular weight and empirical formula of catacandin A were determined by FAB $^{8)}$ mass spectrometry. Both positive and negative ion spectra indicated a molecular weight of 510 for the free acid. The exact mass observed for $\mathrm{C}_{28} \mathrm{H}_{37} \mathrm{~N}_{2} \mathrm{O}_{8}(\mathrm{M}-\mathrm{H})^{-}$was 509.267 (theory 509.265). Catacandin A gave a major fragment at $m / z 98$ in the negative ion FAB mass spectrum. This ion $\left(\mathrm{C}_{4} \mathrm{H}_{4} \mathrm{NO}_{2}\right.$ by high resolution FAB-MS) fragments from the parent as shown by MS-MS ${ }^{9,10)}$ data and is further evidence to support the presence of an acyltetramic acid in catacandin A (Fig. 3). The ion, $m / z$ 98, could arise from a combination of an $\alpha$-cleavage of the C2-C13 bond and a MCLAFFERTY rearrangement involving the $\mathrm{C} 4-\mathrm{C} 5$ bond cleavage with the hydrogen migration. Under identical conditions, tirandamycin also gave a major fragment at $m / z 98\left(\mathrm{C}_{4} \mathrm{H}_{4} \mathrm{NO}_{2}\right)$, arising from the negative ion FAB mass spectrum. This type of fragmentation may be characteristic of tetramic acid antibiotics. Unfortunately, samples of ikarugamycin and capsimycin were not available to test this hypothesis.

The ${ }^{1} \mathrm{H}$ NMR spectrum and a partial structure, 1, for catacandin A are shown in Figs. 2 and 3, respectively. The two four-proton systems, consisting of the protons on C-9 ( $\delta 5.90), \mathrm{C}-10(\delta$ 7.15), C-11 ( $\delta 6.13)$ and C-12 ( $\delta 5.86)$, and on C-14 ( $\delta 6.90), \mathrm{C}-15(\delta 7.35), \mathrm{C}-16(\delta 6.13)$ and C-17 ( $\delta 6.03)$, were established by decoupling experiments. The assignments of the protons on C-14, 15, 16 and 17 are based on a comparison of their chemical shifts with those of analogous protons in tirandamycin ${ }^{7)}$. 
Fig. 2. $400 \mathrm{MHz}{ }^{1} \mathrm{H}$ NMR spectrum of catacandin $\mathrm{A}$ in $\mathrm{CD}_{3} \mathrm{OD}$.

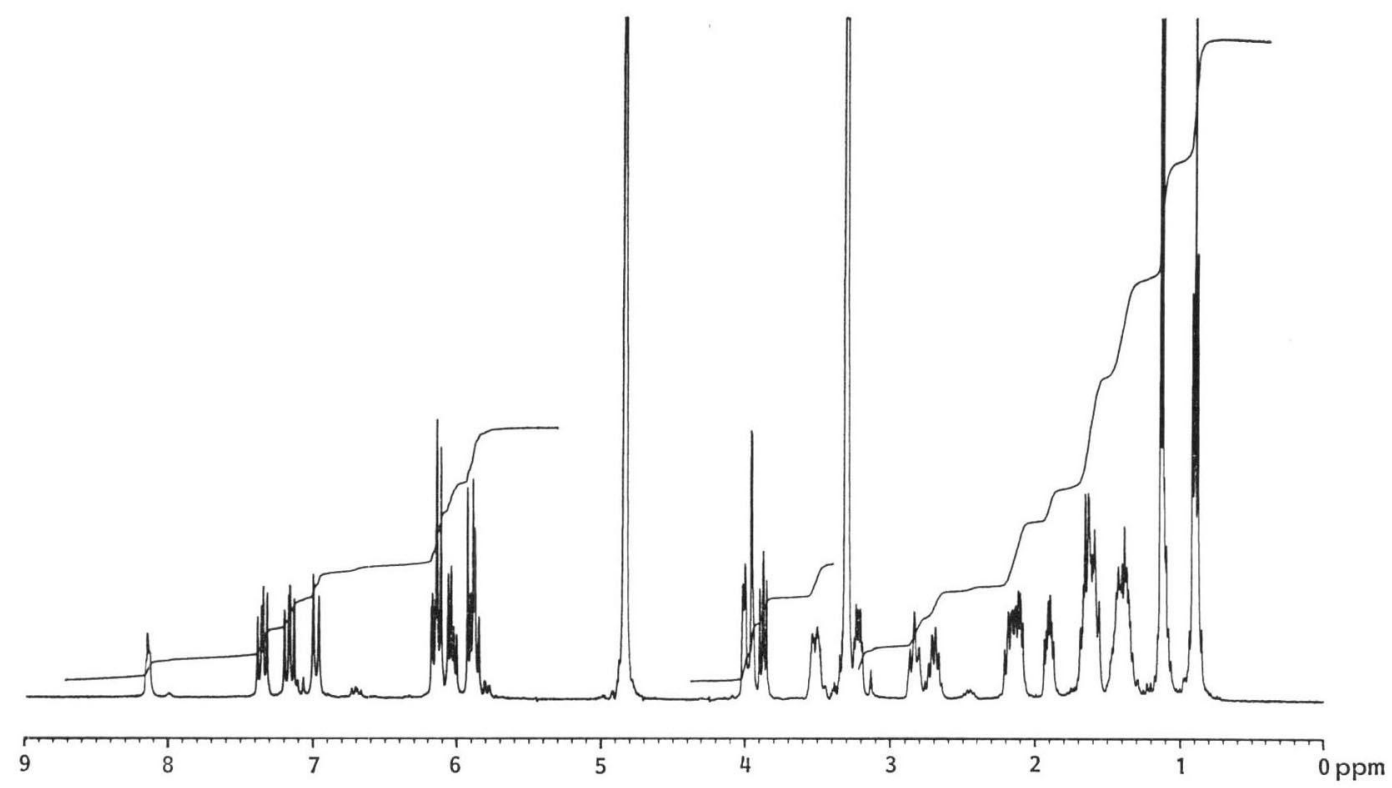

Fig. 3. Partial structure of catacandin A.

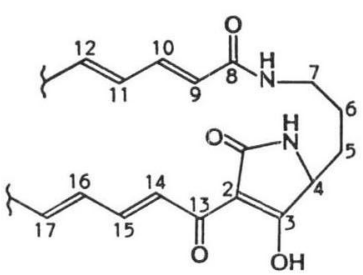

Catacandin A (1)
${ }^{13} \mathrm{C}$ NMR data and partial assignments are presented in Table 2. The multiplicities of the carbons were determined using the Inept ${ }^{11)}$ technique. Assignments of carbons at positions 1 through 4 and 13 through 17 are based on comparison of their chemical shifts with those of analogous carbons in tirandamycin ${ }^{7)}$.

Ozonolysis of catacandin A followed by hydrolysis $^{12)}$ yields ornithine and oxalic acid as

Table 2. ${ }^{13} \mathrm{C}$ NMR data for catacandin A.

\begin{tabular}{|c|c|c|c|c|c|}
\hline $\begin{array}{l}\text { Chemical } \\
\text { shifts }(\delta)^{\mathrm{a}}\end{array}$ & $\begin{array}{c}\text { Carbon } \\
\text { type }^{\mathrm{b}}\end{array}$ & Assignment & $\begin{array}{l}\text { Chemical } \\
\text { shifts }(\delta)^{\mathrm{a}}\end{array}$ & $\begin{array}{c}\text { Carbon } \\
\text { type }^{b}\end{array}$ & Assignment \\
\hline 13.1 & $\mathrm{CH}_{3}$ & & 76.4 & $\mathrm{CH}$ & \\
\hline 19.3 & $\mathrm{CH}_{3}$ & & 101.6 & $\mathrm{C}$ & $C-2$ \\
\hline 27.2 & $\mathrm{CH}_{2}$ & & 122.7 & $\mathrm{C}=\mathrm{C}$ & C-12 \\
\hline 32.2 & $\mathrm{CH}_{2}$ & & 125.2 & $\mathrm{C}=\mathrm{C}$ & C-9 \\
\hline 38.2 & $\mathrm{CH}_{2}$ & & 126.6 & $\mathrm{C}=\mathrm{C}$ & $\mathrm{C}-17$ \\
\hline 41.6 & $\mathrm{CH}_{2}$ & & 130.3 & $\mathrm{C}=\mathrm{C}$ & C-11 \\
\hline 42.1 & $\mathrm{CH}_{2}$ & & 135.9 & $\mathrm{C}=\mathrm{C}$ & C-16 \\
\hline 43.8 & $\mathrm{CH}$ & & 141.0 & $\mathrm{C}=\mathrm{C}$ & C-14 \\
\hline 46.6 & $\mathrm{CH}$ & & 144.5 & $\mathrm{C}=\mathrm{C}$ & $\mathrm{C}-10$ \\
\hline 48.2 & $\mathrm{CH}$ or $\mathrm{CH}_{2}$ & & 147.0 & $\mathrm{C}=\mathrm{C}$ & $\mathrm{C}-15$ \\
\hline 55.6 & $\mathrm{CH}$ & & 167.8 & $\mathrm{C}=\mathrm{O}$ & C-8 \\
\hline 57.3 & $\mathrm{CH}$ & & 174.7 & $\mathrm{C}=\mathrm{O}$ & C-13 \\
\hline 57.4 & $\mathrm{CH}$ & & 176.8 & $\mathrm{C}=\mathrm{O}$ & C-1 \\
\hline 69.8 & $\mathrm{CH}$ & & 194.1 & $\mathrm{C}$ & C-3 \\
\hline 71.7 & $\mathrm{CH}$ & & & & \\
\hline
\end{tabular}

a ppm Downfield from TMS, using dioxane $(67.6 \mathrm{ppm})$ as an internal standard.

b Assignments are made by the Inept technique. 
Fig. 4. $400 \mathrm{MHz}{ }^{1} \mathrm{H}$ NMR spectrum of catacandin $\mathrm{B}$ (ammonium salt) in $\mathrm{CD}_{3} \mathrm{OD}$.

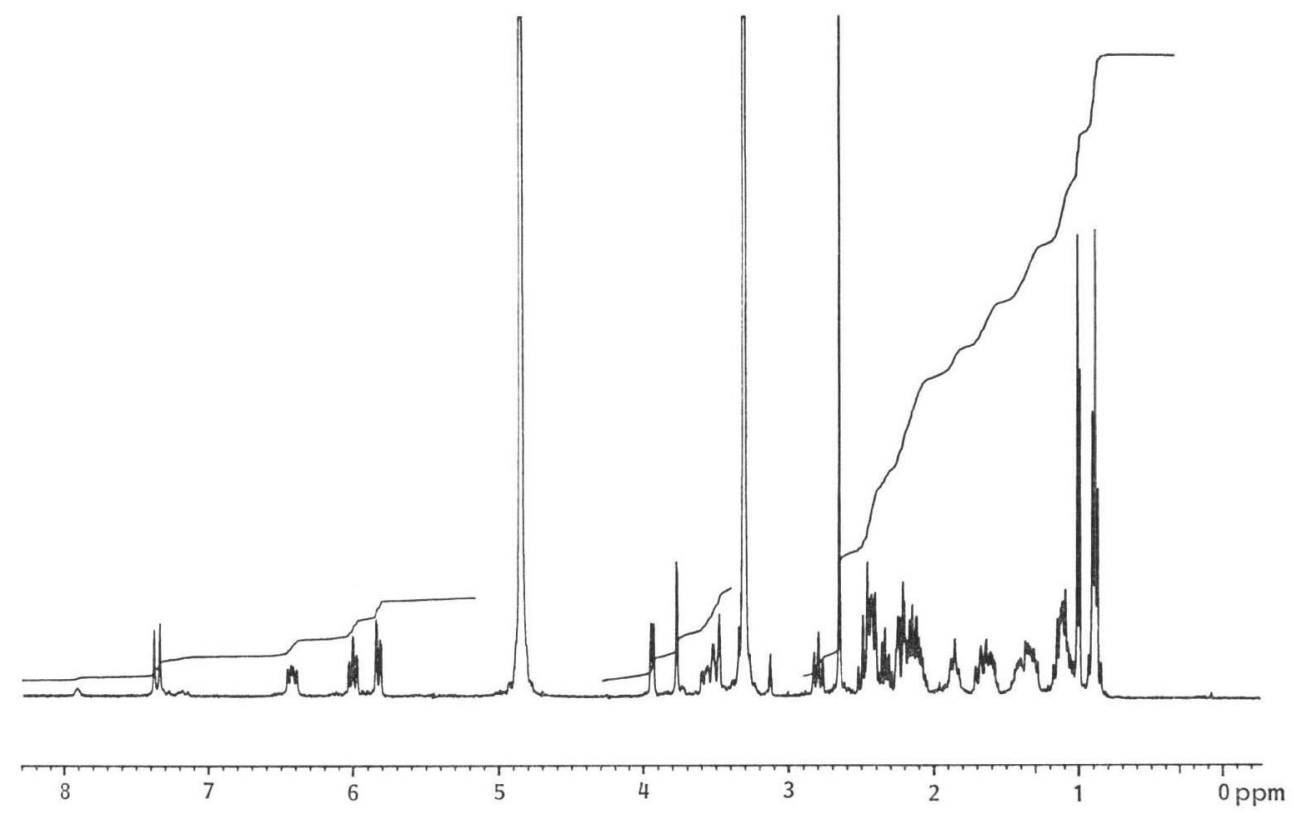

Table 3. In vitro potency of catacandin A and catacandin $\mathbf{B}$.

\begin{tabular}{lcc}
\hline \multirow{2}{*}{\multicolumn{1}{c}{ Organism }} & \multicolumn{2}{c}{ MIC $(\mu \mathrm{g} / \mathrm{ml})$} \\
\cline { 2 - 3 } & $\begin{array}{c}\text { Cata- } \\
\text { candin A }\end{array}$ & $\begin{array}{c}\text { Cata- } \\
\text { candin B }\end{array}$ \\
\hline Candida albicans SC*5314 & 6.3 & 6.3 \\
C. albicans SC9177 & 6.3 & 6.3 \\
C. albicans SC9721 & 6.3 & 6.3 \\
C. albicans SC10102 & 6.3 & 12.5 \\
C. tropicalis SC9861 & 3.1 & 6.3 \\
C. krusei SC2967 & 6.3 & 6.3 \\
C. parakrusei SC2621 & 3.1 & 6.3 \\
C. pseudotropicalis SC11241 & 3.1 & 6.3 \\
C. guilliermondii SC2210 & 6.3 & 12.5 \\
C. glabra SC9342 & 12.5 & 25 \\
Staphylococcus aureus SC1276 & 50 & \\
S. aureus SC2399 & 100 & \\
Escherichia coli SC2927 & 100 & \\
\hline
\end{tabular}

* Squibb culture. well as an unidentified fragment from the remaining portion of catacandin A.

A minor component of the fermentation, catacandin $\mathrm{B}$, is also a methanol soluble, acidic antibiotic. Physico-chemical data are given in Table 1. The IR spectrum indicates the presence of ester $\left(1720 \mathrm{~cm}^{-1}\right)$ and amide $\left(1655 \mathrm{~cm}^{-1}\right)$ functions. A hypsochromic shift of the UV maximum from $324 \mathrm{~nm}$ to $317 \mathrm{~nm}$ in going from acidic to alkaline $\mathrm{pH}$ is indicative of an enoyltetramic acid system as in ikarugamycin ${ }^{12)}$. Comparison of the UV of catacandins $A$ and $B$ indicates a higher degree of conjugated unsaturation for catacandin A. The molecular weight and empirical formula of catacandin $B$ were determined by FAB mass spectrometry. Both positive and negative ion spectra indicated a

molecular weight of 510 for the free acid. The exact mass observed for $\mathrm{C}_{2 \theta} \mathrm{H}_{37} \mathrm{~N}_{2} \mathrm{O}_{8}(\mathrm{M}-\mathrm{H})^{-}$was 509.261 (theory 509.265) and for $\mathrm{C}_{29} \mathrm{H}_{39} \mathrm{~N}_{2} \mathrm{O}_{6}(\mathrm{M}+\mathrm{H})^{+}$was 511.277 (theory 511.280). Thus, catacandins $\mathrm{A}$ and $\mathrm{B}$ are isomeric. The ${ }^{1} \mathrm{H}$ NMR spectrum is shown in Fig. 4.

\section{Biological Properties}

The antimicrobial spectrum of catacandin A and catacandin B is shown in Table 3. Assays were done by a two-fold agar dilution technique, with a medium containing Tryptone $0.5 \%$, malt ex- 
tract $0.3 \%$, glucose $1.0 \%$, yeast extract $0.3 \%$ and agar $1.5 \%$. From the data in Table 3 , it is evident that both catacandins $\mathrm{A}$ and $\mathrm{B}$ are potent anticandidal antibiotics with no significant difference in activity. Although not shown in Table 3, the presence of $50 \%$ calf serum decreased the activity approximately 33 -fold.

\section{Discussion}

The catacandins are acidic antibiotics produced by a bacterium with good anticandidal activity but without appreciable antibacterial activity. It is evident from our studies that they belong to the acyltetramic acid class of antibiotics, but can be unequivocally differentiated from others in this group $^{7,12 \sim 23)}$ by their empirical formula and spectroscopic properties.

\section{Acknowledgments}

We wish to acknowledge Mr. P. A. Principe for supplying fermentation broths, Dr. S. K. TANAKa for in vitro studies, Dr. M. A. Porubcan and Ms. A. Kahle for NMR studies and Dr. S. E. Unger and Mr. T. MCCoRMICK for mass spectral data.

\section{References}

1) Sykes, R. B.; W. L. Parker \& J. S. Wells: $\beta$-Lactam antibiotics produced by bacteria. In Trends in Antibiotic Research. Genetics, Biosyntheses, Actions \& New Substances. Ed., H. UmeZAWA et al., pp. 115 124, Japan Antibiotics Res. Assoc., Tokyo, 1982

2) Tymiak, A. A.; C. A. Culver, J. F. Goodman, V. S. Seiner \& R. B. Sykes: Oxazinomycin produced by a Pseudomonas species. J. Antibiotics 37: 416 418, 1984

3) Tomita, K.; Y. Hoshino, Y. Uenoyama, K. Fujisawa, H. Tsukiura \& H. Kawaguchi: Sorbistin, a new aminoglycoside antibiotic complex of bacterial origin. II. Isolation and taxonomy of sorbistin-producing organism. J. Antibiotics 29: 1147 1151, 1976

4) Shoj, J.; H. Hinoo, R. Masunaga, T. Hattori, Y. WakisaKa \& E. Kondo: Isolation of L-cycloserine from Erwinia uredovora. J. Antibiotics 37: 1198 1203, 1984

5) Meyers, E.; G. S. Bisacchi, L. Dean, W. C. Liu, D. S. Slusarchyk, R. B. Sykes, S. K. Tanaka \& W. H. TREJO: Xylocandin, a new complex of antifungal peptides. Taxonomy, isolation and biological activity. Program and Abstracts of 25th Intersci. Conf. Antimicrob. Agents Chemother., No. 808, Minneapolis, 1985

6) Christensen, P. \& F. D. Cook: Lysobacter, a new genus of nonfruiting, gliding bacteria with a high base ratio. Int. J. Syst. Bacteriol. 28: 367 393, 1978

7) MacKellar, F. A.; M. F. Grostic, E. C. Olson, R. J. Wnuk, A. R. Branfman \& K. L. Rinehart, Jr.: Tirandamycin. I. Structure assignment. J. Am. Chem. Soc. 93: 4943 4945, 1971

8) Barber, M.; R. S. Bordoli, R. D. SedgWick \& A. N. Tyler: Fast atom bombardment of solids (F.A.B.): A new ion source for mass spectrometry. J. Chem. Soc. Chem. Commun. 1981: 325 327, 1981

9) McLafferty, F. W., Ed.: Tandem Mass Spectrometry. John Wiley \& Sons, New York, 1983

10) Tomer, K. B.; F. W. Crow \& M. L. Gross: Location of double bond position in unsaturated fatty acids by negative ion MS/MS. J. Am. Chem. Soc. 105: 5487 5488, 1983

11) Doddrell, D. M. \& D. T. PegG: Assignment of proton-decoupled carbon-13 spectra of complex molecules by using polarization transfer spectroscopy. A superior method to off-resonance decoupling. J. Am. Chem. Soc. 102: 6388 6390, 1980

12) ITO, S. \& Y. Hirata: The structure of ikarugamycin, an acyltetramic acid antibiotic possessing a unique as-hydrindacene skeleton. Bull. Chem. Soc. Jpn. 50: 1813 1820, 1977

13) Stickings, C. E.: Studies in the biochemistry in microorganisms. 106. Metabolites of Alternaria tenuis. Auct. The structure of tenuazonic acid. Biochem. J. 72: 332 340, 1959

14) Rinehart, K. L., Jr.; J. R. Beck, D. B. Borders, W. W. Epstein, T. H. Kinstle, L. D. Spicer, D. Krauss \& A. C. Button: Structure of streptolydigin. Antimicrob. Agents Chemother. -1963: 346 348, 1964

15) Batelaan, J. G.; J. W. F. K. Barnick, J. L. van der BaAn \& F. Bickelhaupt: The structure of the antibiotic K16. II. Chromophore and total structure. Tetrahedron Lett. 1972: 3107 3110, 1972 
16) Schabacher, K. \& A. Zeeck: Lipomycine, II. Die konstitution von $\alpha$ - und $\beta$-Lipomycin. Tetrahedron Lett. 1973: $2691 \sim 2694,1973$

17) Gandhi, N. M.; J. Nazareth, P. V. Divekar, H. Kohl \& N. J. de Souza: Magnesidin, a novel magnesium-containing antibiotic. J. Antibiotics 26: 797 798, 1973

18) Gyimesi, J.; Zs. Méhesfalvi-Vajna \& Gy. Horváth: Reinvestigation of structure of the polyenic antibiotic, oleficin. J. Antibiotics 31: 626 627, 1978

19) Aizawa, S.; H. Akutsu, T. Satomi, T. Nagatsu, R. Taguchi \& A. Seino: Capsimycin, a new antibiotic. I. Production, isolation and properties. J. Antibiotics 32: 193 196, 1979

20) Horváth, G.; M. G. Brazhnikova, N. V. Konstantinova, I. V. Tolstykh \& N. P. Potapova: The structure of nocamycin, a new antitumor antibiotic. J. Antibiotics 32: 555 558, 1979

21) Vesonder, R. F.; L. W. Tjarks, W. K. Rohwedder, H. R. Burmeister \& J. A. Laugal: Equisetin, an antibiotic from Fusarium equiseti NRRL 5537, identified as a derivative of N-methyl-2,4-pyrollidone. J. Antibiotics 32: 759 761, 1979

22) Tsunakawa, M.; S. Toda, T. Okita, M. Hanada, S. Nakagawa, H. Tsukiura, T. Naito \& H. KawaGUCHI: Bu-2313, a new antibiotic complex active against anaerobes. II. Structure determination of Bu$2313 \mathrm{~A}$ and B. J. Antibiotics 33: 166 172, 1980

23) Yokoi, K.; H. Hasegawa, J. Satoh, M. Matsumoto, J. Ohno \& T. Nakajima (SS Pharmaceutical KK): New antibiotic SS8201D. Japan Kokai 84-170,092, Sept. 26, 1984 [World Patents Index 84-278337/45] 